\title{
Communicative tools for organizing a dialogue in network book sand bloginge
}

\author{
L. G. Antonova ${ }^{1}$, K. A. Ryzhenkova ${ }^{1}$
}

1P. G. Demidov Yaroslavl State University, 14 Sovetskaya str., Yaroslavl 150003, Russian Federation

DOI: 10.18255/2412-6519-2021-3-318-325

Research Article

Full text in Russian

The article deals withthe communicative tools for organizing dialoguerelations in network book blogging, which is presented as an active intellectual news platform, a video hosting site that is interesting forits capabilities of educational content and technologies for promoting new products of cinema, theater and book products in the space of virtual discourse. The authors consider the problems of communicative competence of the blogger and the basics of effective communication in the context of blog discourse, present the basic requirements for organizing the news content of the recording, the way of self-presentation and the choice of tools for virtual interaction of the blogger-booktuber with subscribers. When describing the real tools of the virtual dialogue of the blogger-booktuber, the authors refer to the blog discourse of Nikolai Zharinov on the youtubchannele Artifix. On specific examples of video recording, the ways of self-presentation of the blogger, the strategy of his interaction with the target audience, his choice of style and language elements of influence are analyzed. Particular attention is paid to the methods of selection and theme of intellectual content for the programs of this author, the creative features of the individual author's commenting on information. The authors prove that online blogging is a unique communicative environment that allows the blogger to be a creative, self-sufficient competent person, successfully combine the public and intimate in a network dialogue. Each booktuber blogger strives for "effective communication", which is understood as such a dialogue interaction that allows the speaker to achieve the goal and solve a set of communicative tasks: socio-cultural education, successful self-presentation, competent promotion of an intellectual cognitive product-novelties of the book market.

Keywords: virtual discourse; network book blogging; blogger-booktuber; communicative competence of the blogger; educational content; youtubechannel Artifix

INFORMATION ABOUT THE AUTHORS

$$
\begin{array}{r|l}
\begin{array}{r}
\text { Antonova, Liubov G. } \\
\text { (correspondence author) }
\end{array} & \begin{array}{l}
\text { E-mail: antonova_lubov@mail.ru } \\
\text { Doc. Sc. (Pedagogical Sc.), Department chair }
\end{array} \\
\text { Ryzhenkova, Ksenia A. } & \begin{array}{l}
\text { E-mail: kryzhienkova@bk.ru } \\
\text { Student }
\end{array}
\end{array}
$$

Funding: P. G. Demidov Yaroslavl State University, project VIP-011.

For citation: Antonova L. G., Ryzhenkova K. A. Communicative tools for organizing a dialogue in network book sand bloginge // Social'nye i gumanitarnye znanija. 2021. Vol. 7, No 3. P. 318-325. (in Russ.)

(C) Antonova L. G., Ryzhenkova K. A., 2021

This is an open access article under the CC BY license (https://creativecommons.org/licenses/by/4.0/) 


\title{
Коммуникативные инструменты организации диалога в сетевом книжном блогинге
}

\author{
Л. Г. Антонова ${ }^{1}$, К. А. Рыженкова ${ }^{1}$
}

1Ярославский государственный университет им. П. Г. Демидова, ул. Советская, 14, Ярославль, 150003, Российская Федерация

DOI: $10.18255 / 2412-6519-2021-3-318-325$

удК 81.42

Научная статья

Полный текст на русском языке

В статье рассматриваются коммуникативные инструменты организации диалоговых отношений в сетевом книжном блогинге, который представлен как активная интеллектуальная новостная площадка, видеохостинговый сайт, интересный своими возможностями просветительского контента и технологиями продвижения новинок киноискусства, театрального дела и книжной продукции в пространстве виртуального дискурса. Авторы рассматривают проблемы коммуникативной компетентности блогера и основы эффективной коммуникации в контексте блогодискурса, представляют основные требования к организации новостного контента записи, способам самопрезентации и выбору инструментов виртуального взаимодействия блогера-буктьюбера с подписчиками. При описании реальных инструментов виртуального диалога блогера-буктьюбера авторы обращаются к блогодискурсу Николая Жаринова на youtubканале Artifix. На конкретных примерах видеозаписи анализируются способы самопрезентации блогера, стратегии его взаимодействия с целевой аудиторией, выбор им стилевых и языковых элементов воздействия. Особое внимание уделено способам отбора и тематике интеллектуального контента для программ данного автора, креативным особенностям индивидуально-авторского комментирования информации. Авторы доказывают, что сетевой книжный блогинг является уникальной коммуникативной средой, которая позволяет блогеру быть креативной, самодостаточной компетентной личностью, успешно сочетать публичное и интимное в сетевом диалоге. Каждый блогер-буктьюбер стремится к «эффективной коммуникации», под которой понимается диалоговое взаимодействие, позволяющее говорящему достичь поставленной цели и решить комплекс коммуникативных задач: социально-культурного просветительства, успешной самопрезентации, грамотного продвижения интеллектуального познавательного продукта - новинок книжного рынка.

Ключевые слова: виртуальный дискурс; сетевой книжный блогинг; блогер-буктьюбер; коммуникативная компетентность блогера; просветительский контент; Youtube-канал Artifix

ИНФОРМАЦИЯ ОБ АВТОРАХ

\begin{tabular}{r|l} 
Антонова, Любовь Геннадьевна & $\begin{array}{l}\text { E-mail: antonova_lubov@mail.ru } \\
\text { (автор для корреспонденции) }\end{array}$ \\
$\begin{array}{l}\text { Доктор педагогических наук, зав. кафедрой теории } \\
\text { и практики коммуникации }\end{array}$ \\
Рыженкова, Ксения Андреевна & $\begin{array}{l}\text { E-mail: kryzhienkova@bk.ru } \\
\text { Магистрант факультета филологии и коммуникации }\end{array}$
\end{tabular}

Финансирование: ЯрГУ, проект № ВИП-011

Для цитирования: Антонова Л. Г., Рыженкова К. А. Коммуникативные инструменты организации диалога в сетевом книжном блогинге // Социальные и гуманитарные знания. 2021. Том 7, № 3. С. 318-325.

(C) Антонова Л. Г., Рыженкова К. А., 2021

Статья открытого доступа под лицензией СС BY (https://creativecommons.org/licenses/by/4.0/) 
Развитие интернет-коммуникации существенным образом повлияло на современную культуру, в том числе и на культуру получения новостной информации в гуманитарной сфере. Наиболее яркие характеристики переживаемого нами «культурного сдвига», обусловленного возможностями интернет-общения, состоят, по мнению исследователей, прежде в «открытом доступе к разным видам информационного контента» во всемирной электронной сети, возникновении социальных сетей как «общественных структур взаимосвязанных субъектов», а в связи с этим в «изменении соотношения приватности и публичности в разных речевых жанрах при общении в сети» и возникновении «новых форматов и жанров общения» [1, с. 192-193].

Развитие медиасреды и совершенствование медиатехнологий привели к созданию крупных информационных платформ, которые предоставляют пользователям услуги хранения, доставки и показа видеоконтента. К числу таких платформ с широким охватом целевой аудитории относится YouTube - видеохостинговый сайт, пользователи которого могут загружать, просматривать, оценивать, комментировать, добавлять в избранное и делиться теми или иными видеозаписями. Благодаря простоте и удобству использования, YouTube стал популярнейшим видеохостингом и вторым сайтом в мире по количеству посетителей. В числе дополнительных признаков привлекательности следует назвать «интерактивность (возможность общения читателя и автора), высокую степень демократичности общения, отсутствие цензуры (за исключением запретов на перепосты экстремистского содержания), выраженную игровую коммуникативную тональность многих сообщений, высокую скорость распространения информации» [Там же. С. 196-197]. Но для гуманитариев видеохостинговый сайт прежде всего интересен своими возможностями просветительского контента и технологиями продвижения новинок киноискусства, театрального дела и, конечно, книжной продукции.

И в первую очередь встает вопрос о коммуникативной компетентности блогера. Этот вопрос неоднократно рассматривался в числе важных при анализе проблем эффективной коммуникации в блогодискурсе. В первую очередь для успешной коммуникации блогер как языковая личность в интернет-коммуникации должен владеть определенными знаниями, представлениями, умениями и навыками, необходимыми для поддержания общения и обмена информацией в рамках соответствующей ситуации общения. Принято считать, что коммуникативная компетентность языковой личности блогера складывается из трех составляющих: энциклопедической, лингвистической и интерактивной [2, с. 58]. Под энциклопедической компетенцией в данном случае понимается способность человека «вербально описывать положение дел в том или ином фрагменте мира», например, в какой-то предметной области. О лингвистической компетенции пользователя будет непосредственно свидетельствовать способность «правильного использования арсенала определенного языка для достижения тех или иных целей». И самая важная интерактивная - компетенция проявляется в способности участника виртуального дискурса к установлению языкового контакта с партнером по коммуникации при соблюдении правил общения, принятых в данном языковом коллективе. Поскольку речь участников виртуального блогодискурса - это сплав устной и письменной речи, то для адекватной коммуникации в Сети блогер должен знать все эти особенности 
и уметь правильно употреблять и воспринимать эту «новую устно-письменную форму речи» [Там же. С. 59].

И еще одно важное условие успешного блогодискурса, о котором так верно говорит В. И. Карасик, - «возможность выбора информации и источника информирования» и возрастание значимости «карнавализации» и «игровой составляющей в культуре», что неизбежно ведет за собой «развлекательную функцию» в сетевом общении, которая и обеспечивает талантливому блогеру «доминирование в неофициальном общении» [1, с. 163-164].

Таким образом, социальные сети и видеохостинги позволяют блогерам реализовать свое желание представить себя наиболее благоприятным образом; помогают создать персональный «идеальный» образ ведущего благодаря «самопрезентации» перед виртуальным участником разговора. Не обходится здесь без «ювенилизации самопредставления» (В. И. Карасик), что ярко отражается в новых жанрах сетевого дискурса с маркированной креативностью - блогах (сетевых дневниках), пирожках (смешных поэтически оформленных жизненных наблюдениях) и демотиваторах (поликодовых текстах с изображением и подписью к нему, иронически оценивающей картинку). По мнению исследователей, именно «подчеркнутая авторская позиция» комментаторов-блогеров, высокая степень «интертекстуальности сообщений» и обеспечивают тот устойчивый интерес пользователей различных сетевых аккаунтов, которые и принято называть «коммуникативными сообществами, объединенными сходным мировосприятием» их участников [Там же. С. 205].

Именно на таком популярном сообществе, обеспечивающем активный интерес пользователей к чтению как форме «интеллектуального труда» и продвигающем новинки книжной индустрии, мы и остановимся. Контент на ютюбе, имеющий отношение к книжным обзорам, называют буктьюбом (booktube). Соответственно, авторы таких уоutube-каналов - буктьюберы. Это направление стало достаточно популярным в блогодискурсе, но, к сожалению, в этом виде интеллектуального новостного дискурса пока недостаточно профессионалов для организации эффективного качественного интернет-диалога.

Серьезным исключением можно назвать блогодискурс Николая Жаринова 1 на уоutube-канале Artifix [3; 4; 5].

Данный канал демонстрирует все новейшие достижения блогодискурса в направлении популяризации литературы и искусства в режиме интеллектуального новостного сайта. Он насчитывает 641 тысячу подписчиков (на 05.06.2021) и является профессионально-организованным проектом с несколькими ведущими, каждый из которых ведёт свою подрубрику. Важный инструмент организации интернет-диалога - имиджевая концепция журнала, которая ярко и креативно заявлена при входе на портал: «Мы команда влюблённых в искусство людей, которые стремятся поделиться этой любовью со своей аудиторией. Для Artifex нет неинтересных проектов - любое искусство имеет право быть увиденным и услышанным. А мы видим искусство практически во всём и знаем, как правильно его преподнести» [3]. Таким образом, авторы канала позиционируют себя как профессионалы в обла-

\footnotetext{
${ }^{1}$ Николай Жаринов - главный редактор YouTube-канала Artifex Ru, имеет филологическое образование, является преподавателем вуза. Он автор научно-популярных книг: «Исповедь литературоведа...», «Тайная жизнь шедевров...» и др. В течение последних лет занимает одну из первых позиций в рейтинге блогеров- буктьюберов.
} 
сти разных видов искусств, они знают, как привлечь аудиторию к изучению и пониманию произведений искусства и продуктов книжной индустрии. Для подписчиков важно, что устроители позиционируют себя как «профессионалы», а значит, полученной информации на этом канале можно доверять, ее можно использовать, ею можно делиться с другими подписчиками.

Имиджевая заставка, которая сопровождает деятельность канала, выполнена в классической инсталляционной манере со смысловыми видеофайлами и удачно дополняет грамотно созданный имиджевый образ канала в интернет-диалоге со зрителями.

Таким образом, актуализация внешних признаков качественного контента YouTube-канала Artifex Ru позволяет реализовать задачи креативного продвижения информации и «ювенилизациия самопредставления» (В.И. Карасик) в новых формах сетевого дискурса, о чем мы говорили в начале статьи.

Но основной и важнейший инструмент сетевого диалога связан с созданием качественного контента, который, как известно, остаётся в сети и продолжает набирать просмотры и комментарии даже спустя годы после публикации. Не менее значим и выбор своего «особенного» стиля подачи информации и средств воздействия на свою аудиторию.

Все программы Николая Жаринова отличаются непревзойденным вкусом в отборе и подаче новостного контента. Как правило, блогер предлагает интересные обзоры книжных новинок или оригинальную интерпретацию ранее вышедших книг, в которых особое внимание уделено осмыслению философских и историкокультурных проблем.

Так, например, одна из последних его работ - «Топ 10 книг, меняющих жизнь (Исповедь литературоведа)» - посвящена аналитическому разбору известных книг, которые позволяют заново осмыслить прочитанное [5]. Выбирая подобное название для видеопрограммы, автор ориентирует подписчика на продуктивное, смысловое восприятие информации, позволяющее после целенаправленного и креативного просмотра программы осознать роль книги и чтения в жизни человека.

Автор блога оправданно выбирает в качестве жанра интерактивного диалога разговор со зрителем; беседу. На протяжении всего видеоролика собеседники являются полноправными участниками речевого действия, происходит обмен «равноправными», равнозначными репликами, суждениями, размышлениями. Кроме того, ведущий предполагает и реакции «второго адресата» - ждет комментариев зрителей непосредственно в чате на информацию из видеоматериалов, которые демонстрируются в ходе беседы.

Особо следует сказать о выборе тактических приемах организации диалога в программах Николая Жаринова. Как правило, он, как умелый блогер-буктьюбер, выбирает две основные тактики.

Первая, лидирующая, - тактика самопродвижения. Блогер пытается показать зрителю, что он является компетентным в том материале, о котором он рассказывает, так зритель узнает, что перед ним не просто блогер, а специалист-филолог, для которого анализ нового литературного произведения - «интересная и ответственная задача». И эта тактика успешно реализуется, благодаря уверенному, креативному изложению материала и выверенному, но очень самодостаточному в коммуникативном отношении поведению блогера. Так, автор может дать 
свое личное, ассоциативное мнение о книге и часто делает это без опоры на известные литературоведческие подходы в анализе: «Это сплошной, нескончаемый поток ассоциаций, впечатлений, переживаний. Не текст, а извилистая река, в течении которой нарушаются правила русского языка, обрывки советских газет соседствуют с библейскими аллюзиями, кусками подслушанных разговоров» (о романах С. Соколова). Вот, например, как автор анализирует концепцию нашумевшего романа Джулиана Барнса «Нечего бояться»: «Наверное, каждый из людей думал о своих последних словах. Покинуть этот мир с напутствием, уйти изящно, как Чехов, с бокалом шампанского, или Оскар Уайльд, бросивший вызов занавескам» [5].

В дополнении к такому нетрадиционному анализу текста - ироничный тон, который часто сменяет эпическую тональность беседы, что помогает блогеру «уравновесить» содержательную плотность информативного текста. Например: «Вообще, читать Достоевского в тот момент, когда Вам не очень хорошо на душе, с одной стороны, может быть, и не совсем правильным решением, но с другой стороны, а вдруг поможет...» [Там же]. Эта фраза была сказана блогером с шуточным подтекстом, но все правильно понимают смысловое наполнение этого высказывания в концептуальном поле программы.

Вторая тактика, дополняющая диалоговую стратегию поведения, - тактика гомилетическая (пояснение примером, разъяснение). Николай Жаринов, как умелый автор познавательной программы, пытается доказать, что чтение - интереснейшая интеллектуальная деятельность, которая обеспечивает человеку серьезное саморазвитие. Обратим внимание, что этой тактики придерживаются все блогерыбуктьюберы, поскольку основная функция подобных программ - просветительская. В анализируемом видеофрагменте пояснение и разъяснение сопровождает анализ сюжетной лини книги и характеристики трудного авторского подтекста. Вот характерная для блогера оценочная фраза: «Это книга, полная грусти, бездонной тоски человека, столкнувшегося с бездной, но не нашедшего веру, потому что выбор безверия был выбором сердца». Кроме того, автор канала, описывая книгу, может сказать, как эта книга «отразилась» на его жизненной эстетике: «Следующая книга, мимо которой вообще не могу пройти, потому что это было уже то, что полностью перевернула моё сознание...» или «Курт Воннегут. «Бойня номер пять». То, что нужно прочитать и что точно изменит Ваше мировоззрение» [Там же]. Когда зритель видит подобные фразы-откровения и признания, это, во-первых, вызывает большее доверие, поскольку автор поделился чем-то личным, а во-вторых, такие реплики, несомненно, дополнительный словесный стимул к выбору книги и ее прочтению.

Итак, автором были использованы именно эти тактики диалогового поведения, поскольку буктьюбинг, как интегрированная модель блогодискурса, объединяет стратегии информирования и воздействия и стратегию приватности с предпочтением непринужденного и доверительного общения.

Тактические приемы организации диалога хорошо «поддерживаются» грамотным отбором языковых элементов, которые подчеркивают креативный вербальный имидж блогера, говорящего на одном языке со своими подписчиками.

Например, к числу вербальных приемов интимизации диалога следует отнести использование молодежного сленга или разговорных прецедентов: спойлерить, 
финишить, явная белиберда, дешёвую поделку из серии «помоги-себе-сам»; эмоционально-оценочные слова: вау, бум, хорош. В ходе интеллектуальной беседы они прекрасно «соседствуют» с книжной лексикой: эстетика, фальшь; публицистическими мотивационными установками: поверьте, учиться хорошо - это того cmoum; хорошего вам учебного года, готовьтесь к школе; читайте правильные книги и риторическими вопросами и утверждениями: но куда приводит его это милосердие?; что значит, быть приговорённым к смерти?; что значит возродиться?; а в итоге?; выражено удивительное человеколюбие... [5].

Особое место в вербальном паспорте говорящего занимают развернутые оценочные реплики: «я очень люблю этот роман по многим причинам...»; «самое интересно в Достоевском то, что...»; «в этом романе как будто нет ни капли радости...»; «с одной стороны..., но с другой...»; «лично для меня это...»; «а вот это и интересно»; «это же, наверно, самая лучшая картина понимания»; «книги Достоевского - это не мотивационные книги». Не менее значимы активные диалоговые пристройки к собеседникам: «и, знаете что?», «сейчас я постараюсь пояснить, как именно это происходит»; «вы не видите следов...»; «ваш взгляд прикован к мельчайшим деталям...»; «и вам, действительно, хочется сбежать»; «и вот, мы видим с вами...»; «когда вам не очень хорошо на душе...»; «вот ещё одна интересная деталь»; «и теперь смотрите...»; «и снова мы получаем отсылку к...»; «вы знаете, этот год уникальный...»; «мы обязательно вернёмся к вам еще раз...» [3].

Как мы видим, в речи ведущего программы встречаются разнообразные лексические элементы. Принципы дискурса и диалога требуют естественного тона общения, выбора устно-речевых оборотов речи с целью сохранения научно-популярного, доверительного и дружеского контекста медийного диалога.

\section{Выводы}

Сетевой блогодискурс представляет собой общение в социальной сети в структуре взаимосвязанных субъектов, имеющих общие интересы. Электронный режим общения существенным образом повлиял на способы и содержание такой коммуникации. В сетевом блогодискурсе, благодаря возможности общения в социальных медиа напрямую, между блогерами и их подписчиками произошло размывание границ между публичностью и приватностью: получить ответ на выступление, публикацию или проблемный вопрос можно непосредственно в чате при просмотре или в комментариях сразу после эфира. Это значительно повышает «режим доверия» участников виртуального диалога.

Успешная коммуникация в блогодискурсе поддерживается грамотно выбранными креативными приемами коммуникативного поведения блогера: ярко выраженной авторской позицией, открытой аргументацией, оценочностью, нестандартностью в стилевом и жанровом оформлении записи. Все эти тактические приемы в организации эффективного успешного блогодискурса и экспрессивные средства воздействия обеспечивают востребованность того или иного канала, злободневность и актуальность его информационного контента и в итоге могут сделать блогера и его сайт узнаваемыми и популярными.

Важные наблюдения были сделаны при аналитическом описании сетевого книжного блогинга буктьюбера Николая Жаринова на youtube-канале Artifix. Автор-блогер как личность, активно взаимодействующая с своими подписчиками 
в блогодискурсе, грамотно эффективно использующая тактические приемы самопрезентации и просветительского сопровождения, действительно успешно и грамотно сможет преподнести себя массовой аудитории и продемонстрировать свою коммуникативную компетенцию и успешный опыт сетевого диалога.

Наша практика прикладного описания сетевого интерактивного взаимодействия подтверждает, что в лучших примерах блогодискурса перед массовой аудиторией предстает креативная личность автора-блогера, который искренне заинтересован в представлении и анализе актуальных гуманитарных и социокультурных проблем и стремится найти им разумное объяснение и решение в просветительском диалоге со своими подписчиками.

\section{Ссылки / References}

1. Карасик В. И. Языковые мосты понимания: монография. М.: Дискурс, 2019. 524 с.

2. Лутовинова О. В. Коммуникативное пространство виртуальной языковой личности // Известия ВГПУ. 2012. № 11. URL: http://cyberleninka.ru/article/n/kommunikativnoeprostranstvo-virtualnoy-yazykovoy-lichnosti (дата обращения 20.07.21).

3. Жаринов Н. Достоевский «Идиот» [Исповедь литературоведа] // YouTube. URL: https://www.youtube.com/watch?v=fspa_1fKdvw\&t=423s. (дата обращения: 30.05.2021).

4. Жаринов Н. Толстой vs Ницше I Горький «На дне» [Исповедь литературоведа] // YouTube. URL: https://www.youtube.com/watch?v=N162o4IBfes\&t=1s (дата обращения: 30.05.2021).

5. Жаринов Н. Топ 10 книг, меняющих жизнь [Исповедь литературоведа] // YouTube. URL: https://www.youtube.com/watch?v=yddFxeeAhVQ\&list=WL\&index=2\&t=90s. (дата обращения: 30.05.2021). 